\title{
Performance of a high resolution global model over southern South America
}

\author{
Josefina Blázquez* and Mario N. Nuñez \\ Centro de Investigaciones del Mar y la Atmósfera (CIMA-CONICET/FCEN-UBA), Departamento de Ciencias de la Atmósfera y los Océanos \\ (FCEN-UBA), Instituto Franco Argentino del Clima y sus Impactos (UMI IFAECI/CNRS), Ciudad Universitaria, Buenos Aires, Argentina
}

\begin{abstract}
This paper evaluates a present climate simulation over southern South America performed with the Meteorological Research Institute/Japanese Meteorological Agency (MRI/JMA) high resolution global model. Main patterns of low and upper-level atmospheric circulation were analysed in a 25-year simulation as well as climate means, interannual variability, trends and bias of temperature and precipitation. The model is able to reproduce the main atmospheric circulation patterns and mean surface variables, although some deficiencies were found such as an overestimation of temperature over central Argentina in most of seasons, an overestimation of austral winter precipitation over northeastern and central Argentina, an underestimation of precipitation in all the seasons over southeast of Brazil, an underestimation of the amplitude of the annual cycle temperature in some regions and an overestimation of the amplitude of the annual cycle of precipitation over mountainous areas. Model interannual variability was also assessed. In general, temperature variability is overestimated, whereas precipitation is underestimated. The spatial structure of the year-to-year variability of precipitation is correctly simulated by the model, although some patterns were misplaced. Most of regions present a cold seasonal bias reaching values of $-2{ }^{\circ} \mathrm{C}$ in some regions. It was found that precipitation biases are between 3 and $-1 \mathrm{~mm} \mathrm{day}^{-1}$. In some regions and seasons observed and simulated temperature trends coincide, as in austral summer or spring, where the model and the observations show positive trends in most of regions. However, there is no agreement between observed and simulated precipitation trends in almost all the regions and seasons. Copyright (C) 2012 Royal Meteorological Society
\end{abstract}

KEY WORDS global model; validation; present climate; southern South America

Received 26 February 2011; Revised 22 December 2011; Accepted 28 February 2012

\section{Introduction}

Nowadays climate models are the main tool to analyse the behaviour of meteorological events and to study their development and evolution. They are also successfully used in short- and medium-term weather forecast. In recent years they have been used to evaluate the impact of increased anthropogenic greenhouse gas emissions to the atmosphere. Models are reliable because they are based on physical principles and they have the ability to represent both the current climate and past climate changes.

In general, the resolution of global climate models (GCMs) is too coarse (between $1^{\circ}$ and $4^{\circ}$ ) to represent changes on regional scales. Consequently, regional climate models and high resolution GCMs are used to improve the spatial detail of the simulated climate. In particular, high resolution over southern South America is necessary to represent the complex topography of the Andes. This narrow but high mountain chain plays a very important role in the South American climate, especially

\footnotetext{
* Correspondence to: J. Blázquez, Centro de Investigaciones del Mar y la Atmósfera (CIMA-CONICET/FCEN-UBA), Departamento de Ciencias de la Atmósfera y los Océanos (FCEN-UBA), Instituto Franco Argentino del Clima y sus Impactos (UMI IFAECI/CNRS), Ciudad Universitaria, Buenos Aires, Argentina.

E-mail: blazquez@cima.fcen.uba.ar
}

at low levels [e.g. the low-level jet (LLJ) is channelled southward by the Andes, Section 4.1.1].

Over South America, Labraga and Lopez (1997), Carril et al. (1997), Bidegain and Camilloni (2006), Vera et al. (2006a), Seth et al. (2010) are the few authors who have been assessed the present climate and the future climate changes by using global models. The particularity of these studies is that they were done with global models with coarse resolution. It is known that if the representation of physical processes is the same, the increment in the resolution of models could imply a better representation of many features of topography and therefore of the main characteristics of atmospheric circulation, the principal patterns of precipitation and temperature, etc. Recently, Kitoh et al. (2011) have analysed the projections for precipitation with the Meteorological Research Institute high resolution atmospheric global model (MRIAGCM) over South America. They found that this model reproduces the maximum of austral winter precipitation located over southeastern South America which other global or regional models can not represent adequately (Vera et al., 2006a; Silvestri et al., 2008; Solman et al., 2008). On the other hand, many authors have been performing experiments with regional climate models over the region. Solman et al. (2008) and Nuñez et al. (2009) carried out 10-year numerical simulations (present and 
future) to obtain climate change projections for the period 2081-2090 with respect to the mean climate of decade $1981-1990$. In addition, based on the simulations by Solman et al. (2008) and Nuñez et al. (2009), Cabré et al. (2010) used the pattern scaling technique to estimate near future climate changes. Those authors achieved improved representations of climate, compared with low resolution global models, thanks to the greater spatial detail of regional models. Furthermore, Silvestri et al. (2008) simulated the current climate over South America with the MPI (Max Planck Institute) regional climate model (REMO) concluding that this model may be a useful tool for climate change simulations, and Marengo et al. (2009) studied the changes in temperature and precipitation extremes through PRECIS (Providing Regional Climates for Impacts Studies) regional model with two emission scenarios (A2 and B2).

The first step to understand climate changes that are likely to occur in the future is the assessment of the present climate. Such assessment also allows determining the model deficiencies, among other topics. For this reason, this paper provides an evaluation of a present climate simulation over southern South America performed with the Japanese Meteorological Agency (JMA)/MRI high resolution global model.

This study is organized as follows: Section 2 describes some model characteristics and provides some details of the experimental design, while the data used to validate the model and the methodology applied are described in Section 3. Section 4 concentrates on assessing the quality of model simulations of mean climate, interannual variability, trends as well as on quantifying the seasonal bias of the simulations, mainly using precipitation and temperature variables. Finally, the summary and conclusions can be found in Section 5.

\section{Model and experimental design}

The model of the JMA and the MRI is used in this study. It is a global atmospheric model with a horizontal grid size of about $20 \mathrm{~km}$ (TL959) and 60 levels (L60) in the vertical with the model top at $0.1 \mathrm{hPa}$. The model is hydrostatic, and uses a prognostic Arakawa-Schubert scheme for cumulus convection. The scheme of Mellor and Yamada (1974) and Mellor and Yamada (1982) is used to parameterize the boundary layer; the land surface is described by the Simple Biosphere ( $\mathrm{SiB}$ ) model following Sato et al. (1989a, 1989b). For the present climate simulation, 25 years of historical sea surface temperature (SST) observations (from 1979 to 2003) from the HasISST1 database (Rayner et al., 2003) were fed into the model. The global model was run in the Earth Simulator, which was the fastest supercomputer in the world from 2002 to 2004 . It takes about $4 \mathrm{~h}$ to execute a 1-month integration of the TL959L60 model using only 30 of its 640 processor nodes. For more details on model setup see Mizuta et al. (2006).

\section{Data and methodology}

High resolution JMA/MRI global model outputs were used to evaluate the present climate of southern South America. These simulated data were compared with observed daily temperature and precipitation provided by the National Meteorological Service of Argentina, the National Center for Atmospheric Research (NCAR), the National Water Agency from Brazil and the CLARISLPB project (A Europe-South America Network for Climate Change Assessment and Impact Studies in La Plata Basin). More than 1200 precipitation stations and 200 temperature stations were selected to carry out this assessment. The reason for having much more precipitation observations than temperature is that most of the former were obtained from the National Water Agency database, which only has precipitation data. Last but not least it is worth mentioning that several gaps were found in the 1979-2003 data series. Such gaps contribute to restrict the evaluation of model performance over some regions in southern South America. It is worth to mention that these dataset were also used in other studies over South America (Silvestri et al., 2008; Penalba and Robledo, 2010) which ensures that the validation of the model will be reliable. For assessing the spatial distribution of interannual variability of precipitation, GPCP (Global Precipitation Climatology Project) version 2.1 data (Adler et al., 2003) was used. This data base consists of a precipitation dataset of monthly means from combined satellite/station data with spatial resolution of $2.5^{\circ}$. Finally, data from the European Centre Medium Range Weather Forecasts (ECMWF) 40-year Reanalysis (ERA40) (Uppala et al., 2005) were also used to evaluate the atmospheric circulation of the JMA/MRI model. These data are available in a $1.125^{\circ} \times 1.125^{\circ}$ global grid

To assess temperature and precipitation simulations, values at grid points located nearest to the measurement stations were compared. The standard deviation was calculated for the 25 years to analyse the interannual variability. In particular, for precipitation the standard deviation normalized by the 25-year average, called coefficient of variation (CV) was used. These calculations were done following Giorgi et al. (2004). Linear climate trends were calculated by adjusting a least square line to the 25 year data series.

\section{Results}

\subsection{Mean climate}

\subsubsection{Atmospheric circulation}

Atmospheric circulation in South America presents different patterns, which need to be well represented by the models. To examine the performance of the MRI/JMA model in representing upper- and lower-level atmospheric circulation, observed and simulated wind speed 
(a) $\quad$ MRI/JMA model

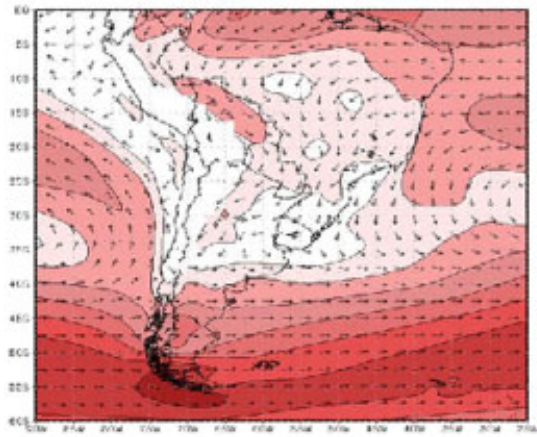

(c)

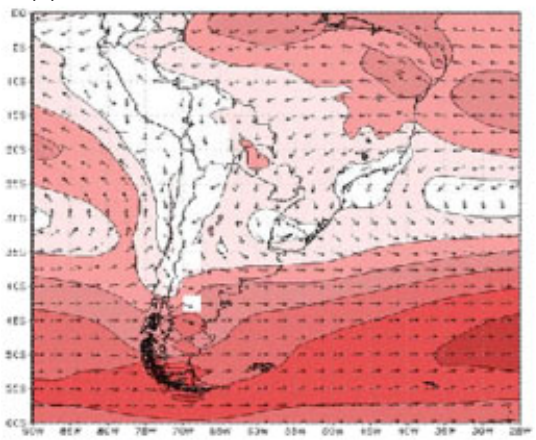

(e)

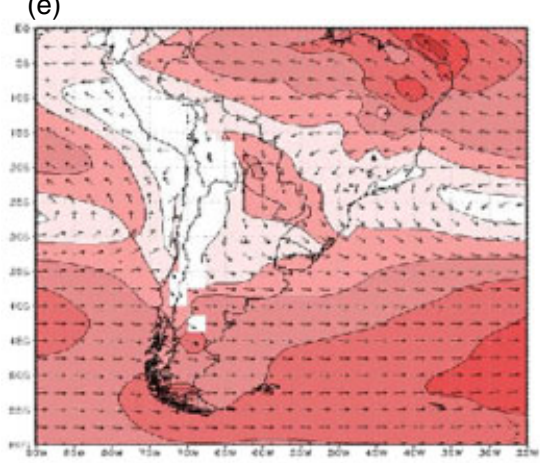

(g)

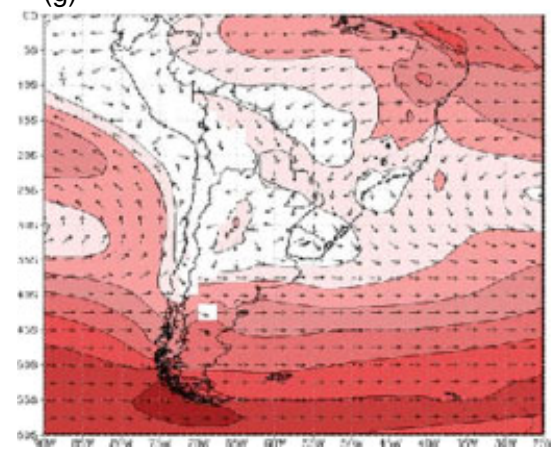

(b) ERA 40 reanalysis

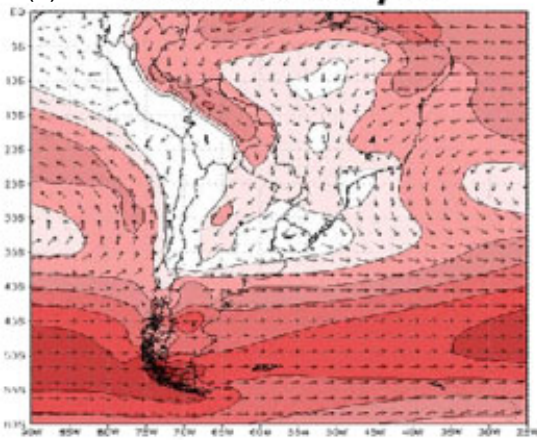

(d)

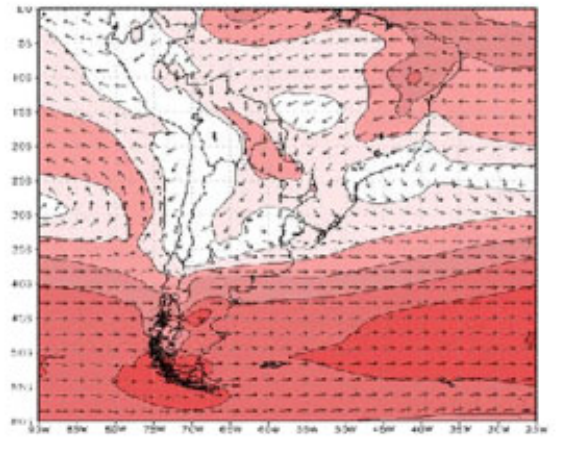

(f)

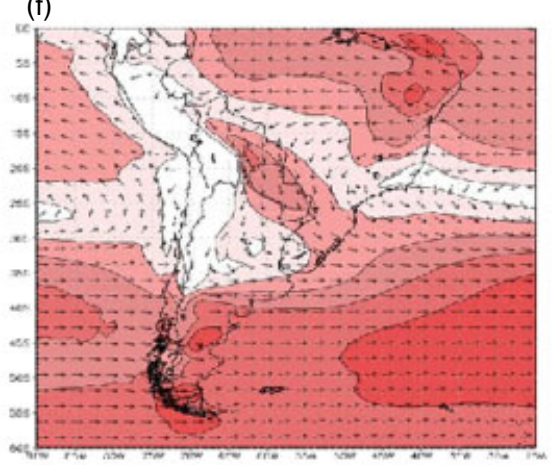

(h)

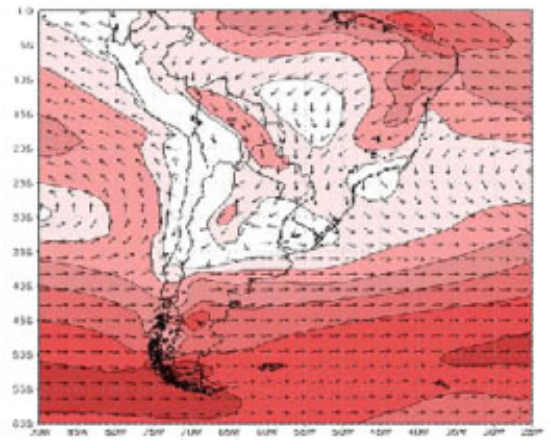

Figure 1. Mean $850 \mathrm{hPa}$ wind speed in $\mathrm{m} \mathrm{seg}^{-1}$ (shaded) and direction (arrows) from the MRI/JMA model (left panel) and ERA40 reanalysis (right panel) for the period 1979-1999. DJF (a, b); MAM (c, d); JJA (e, f); SON (g, h). This figure is available in colour online at wileyonlinelibrary.com/journal/joc

and direction for austral summer (December-JanuaryFebruary, DJF), autumn (March,April-May, MAM), winter (June-July-August. JJA) and spring (SeptemberOctober-November, SON) were compared (Figures 1 and 2).

In particular, Figure 1 displays the $850 \mathrm{hPa}$ wind speed and direction for the MRI/JMA model and ERA40 reanalysis in the period 1979-1999. The LLJ is an important feature of low-level circulation over South America, since it doubles the precipitation amounts in central Argentina (Liebmann et al., 2004) and increases the frequency of mesoscale convective systems in DJF (Salio et al., 2007). The model represents the LLJ in all the seasons but it underestimates the jet speed. This 
(a) MRI/JMA model

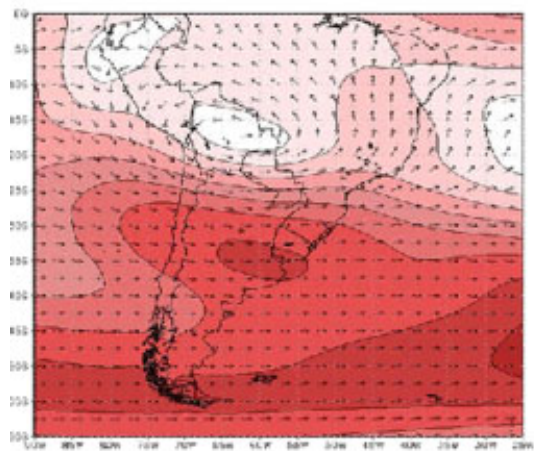

(c)

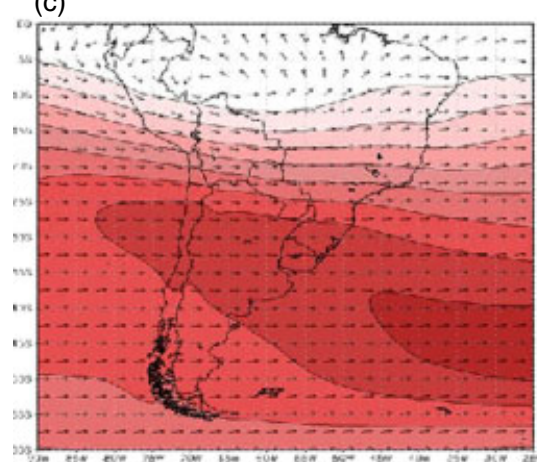

(e)

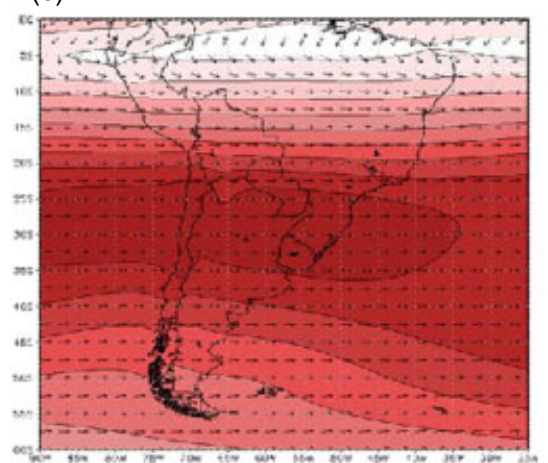

(g)

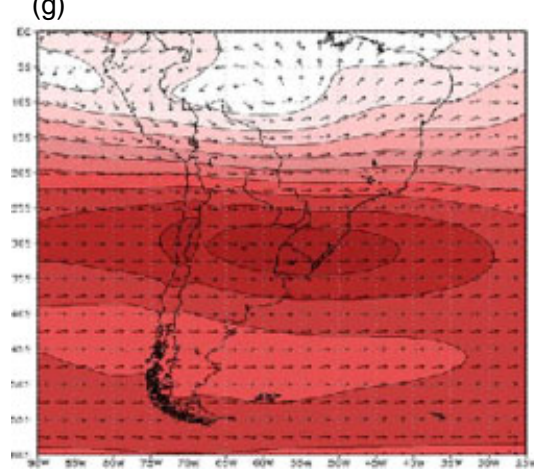

(b) ERA 40 reanalysis

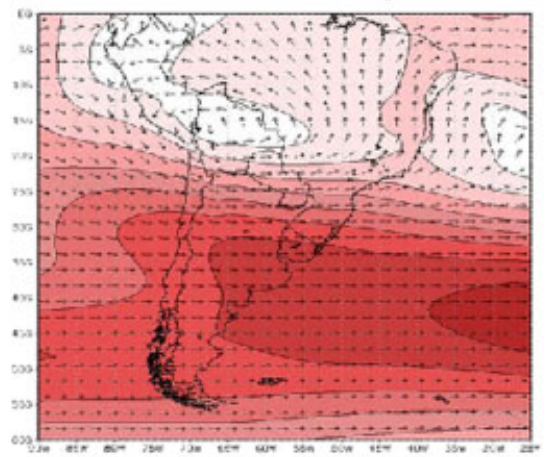

(d)

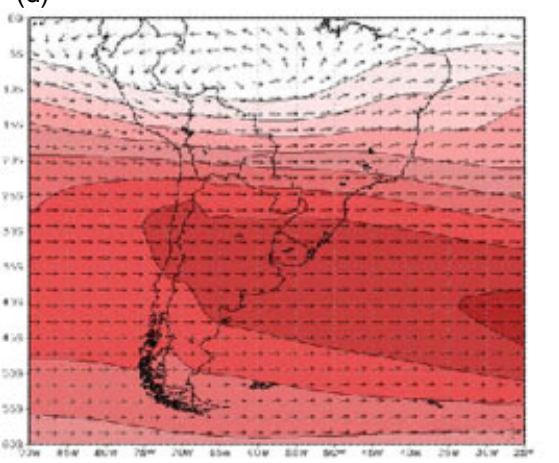

(f)

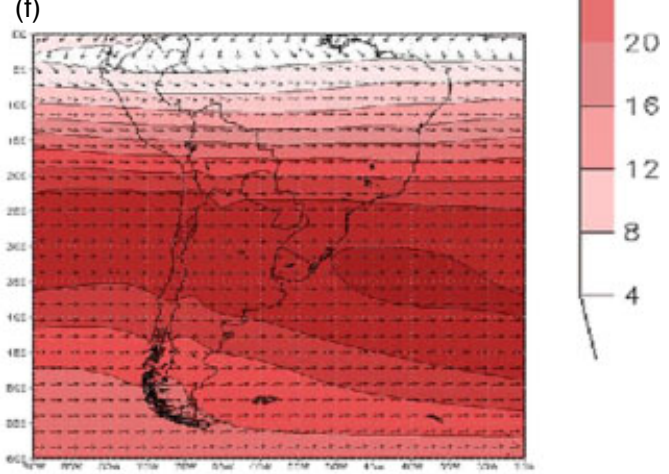

(h)

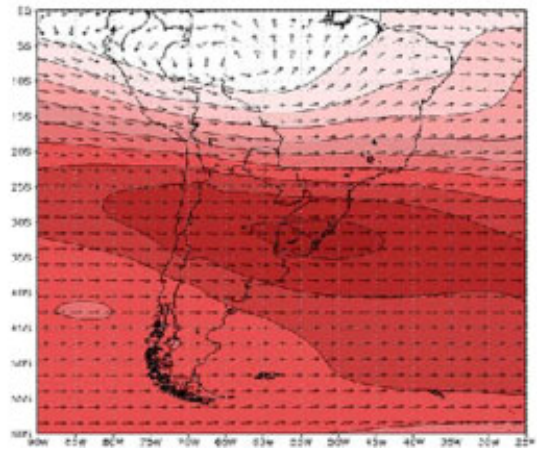

Figure 2. Mean $200 \mathrm{hPa}$ wind speed in $\mathrm{m} \mathrm{seg}^{-1}$ (shaded) and direction (arrows) from the MRI/JMA model (left panel) and ERA40 reanalysis (right panel) for the period (1979-1999). DJF (a, b); MAM (c, d); JJA (e, f); SON (g, h). This figure is available in colour online at wileyonlinelibrary.com/journal/joc

underestimation was also found by Silvestri et al. (2008) using REMO model. Westerlies are another feature of low-level circulation. They reach the continent south of $40{ }^{\circ} \mathrm{S}$ approximately, where the Andes are lower. Figure 1 shows that the simulated location of the westerlies is correct but the speed is underestimated or overestimated in some areas south of $40^{\circ} \mathrm{S}$. The model is also able to represent the anticyclonic gyres over both the Atlantic and the Pacific Oceans.

The main feature of DJF upper-level circulation is the Bolivian High which is primarily determined by Amazonian precipitation (Lenters and Cook, 1997; Gandu and 
(a) DJF

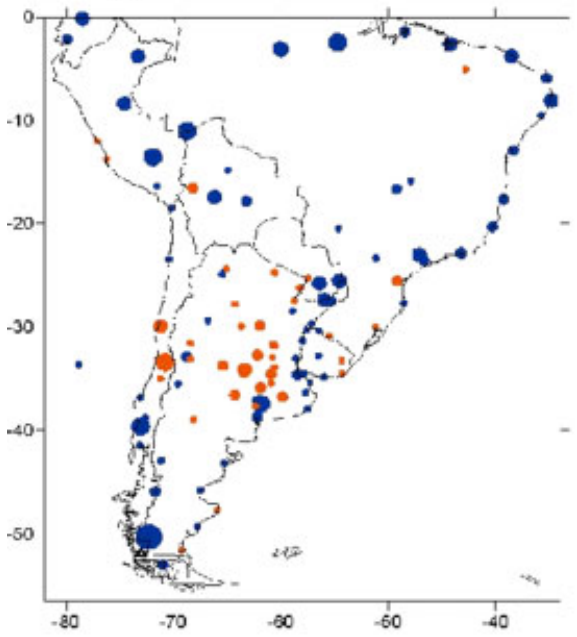

(c) JJA

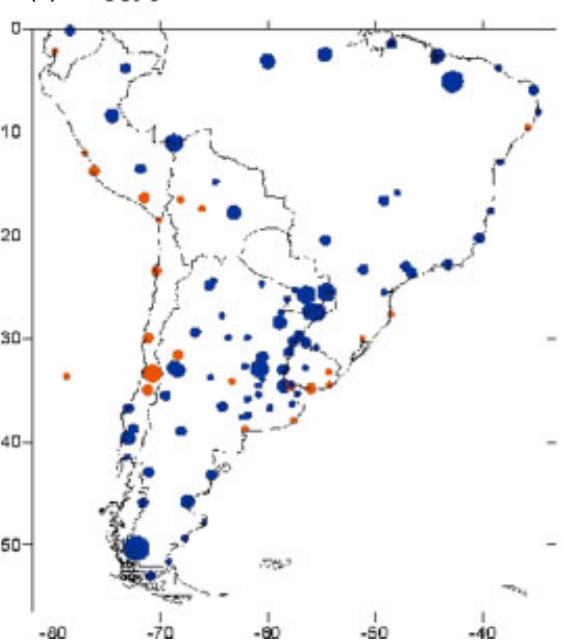

(b) MAM

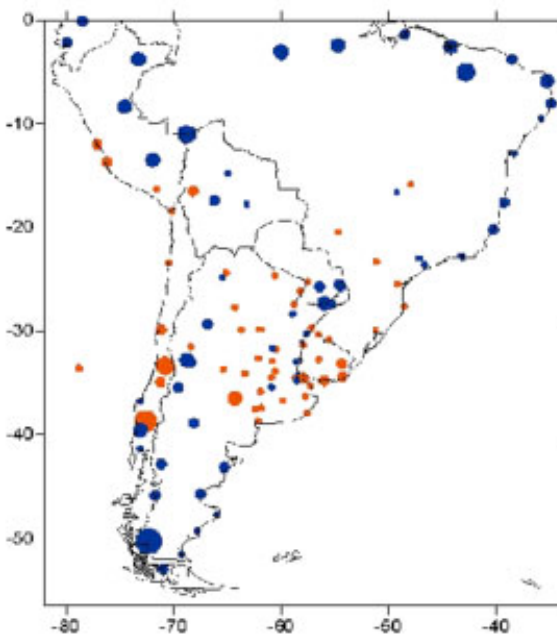

(d) SON

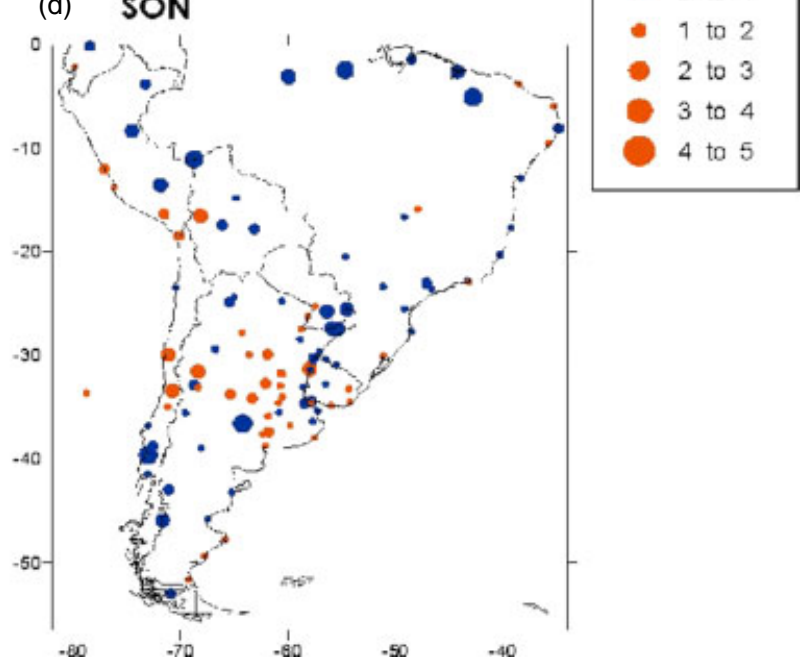

Figure 3. Differences between simulated and observed mean surface air temperature $\left({ }^{\circ} \mathrm{C}\right)$ for the period $1979-2003$ for the seasons DJF, MAM, JJA and SON. This figure is available in colour online at wileyonlinelibrary.com/journal/joc

Silva Dias, 1998). Figure 2 shows the speed and direction of wind at $200 \mathrm{hPa}$ for all the seasons from both the MRI/JMA model and ERA40 reanalysis. In DJF, the location of the Bolivian High is correct in the model simulation; the intensity of the High is reasonably well reproduced (Figure 2(a) and (b)). The model also performs well simulating the Bolivian High in SON and MAM (Figure 2(c), (d), (g) and (h)), capturing the displacement to the north. On the other hand, the upper-level circulation in JJA is also characterized by the westerlies, which are reasonably well captured by the model, although in this case the MRI/JMA model overestimates the wind speed over central Argentina (Figure 2(e) and (f)).

\subsubsection{Temperature}

Figure 3 displays differences between simulated and observed seasonal mean surface air temperature for the period 1979-2003. Broadly speaking, small differences - between 2 and $3{ }^{\circ} \mathrm{C}$ - can be found over central and eastern Argentina and over Uruguay. In particular, in DJF, the model underestimates the surface air temperature in the east of Argentina, west of Uruguay, south of Chile and over tropical latitudes, while overestimates are observed over central Argentina. Although this overestimation is also found in other climatic simulations with regional models (De Sales and Xue, 2006; Silvestri et al., 2008; Solman et al., 2008; Pesquero et al., 2009; Alves and Marengo, 2010; Solman et al., 2011), it is worth to mention that over central Argentina the differences of MRI/JMA global model are smaller than in mentioned studies. Similar behaviour in DJF is found in transition seasons. On the other hand, in JJA, the model tends to underestimate the temperature over most of Argentina, south of Chile and to the north of $20^{\circ} \mathrm{S}$. The model's cold biases over central Argentina is not in agreement with that found by other authors (Silvestri et al., 2008; Solman et al., 2008), but is in agreement to the results found by Alves and Marengo (2010).

Figure 4 shows the annual cycle of the mean surface air temperature (1979-2003) for both the model and observations, for southeastern South America (SESA), central Argentina (CARG), Andes (AN), the subtropical region (ST) and Patagonia (PAT). These regions were 

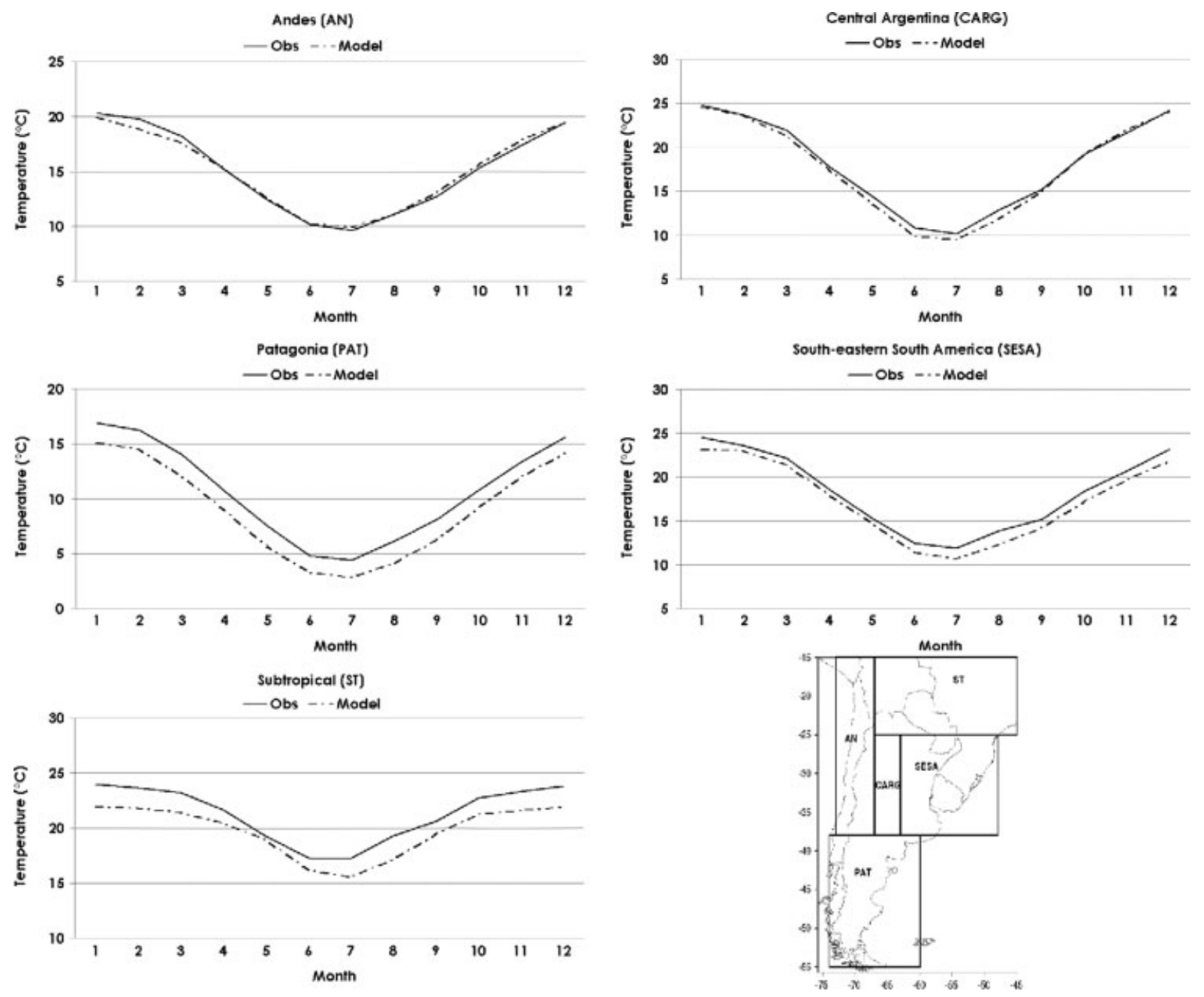

Figure 4. Annual cycle for mean surface air temperature $\left({ }^{\circ} \mathrm{C}\right)$ for the period 1979-2003. Dashed-dotted lines represent the simulation and solid lines the observations.

chosen following the selection of Solman et al. (2008) (The regions are included in Figure 4 herein). The phase of the annual cycle of observed mean surface air temperature is well captured by the MRI/JMA model, although underestimate air temperature at every month of the year in ST, SESA, and PAT regions. Solman et al. (2008) have analysed the Fifth-generation Pennsylvania-State University-NCAR non-hydrostatic Mesoscale Model (MM5) regional model simulation over these regions and in opposition with the MRI/JMA result, they found an overestimation of temperature over SESA and PAT regions. It could be seen from Figure 4 that in CARG region MRI/JMA global model only underestimates the air temperature in MAM and JJA and in the AN region, in January, February and March. It is worth noting, that differences in the AN region are very small. In fact, AN is the region where the model best captures the behaviour and values of the annual cycle of surface air temperature in this region.

\subsubsection{Precipitation}

Kitoh et al. (2011) found that this model reproduces the main spatial patterns of precipitation over South
America. During DJF, the model captures maximums located over SACZ (South Atlantic Convergence Zone), ITCZ (Intertropical Convergence Zone) and over the Amazon. Finally, as it was said previously, an important feature of JJA precipitation is captured by this model: the maximum related to synoptic activity (Vera et al., 2002) located over southeastern South America which other global or regional models can not represent adequately (Vera et al., 2006a; Silvestri et al., 2008; Solman et al., 2008).

Figure 5 displays the percentage ratio between simulated and observed mean precipitation for the mean seasonal in the period 1979-2003. The ratio $d$ is defined as

$$
d=\left(\frac{\bar{X}_{\text {model }}}{\bar{X}_{\text {obs }}}\right) \times 100
$$

where $\bar{X}_{\text {model }}$ and $\bar{X}_{\text {obs }}$ are the simulated and observed mean precipitation, respectively. Values of $100 \%$ indicate that there is no difference between simulations and data. Except for JJA, the remaining seasons present values of percentage ratio close to $100 \%$ over the northeast of Argentina and Uruguay, while the rest of the studied area 


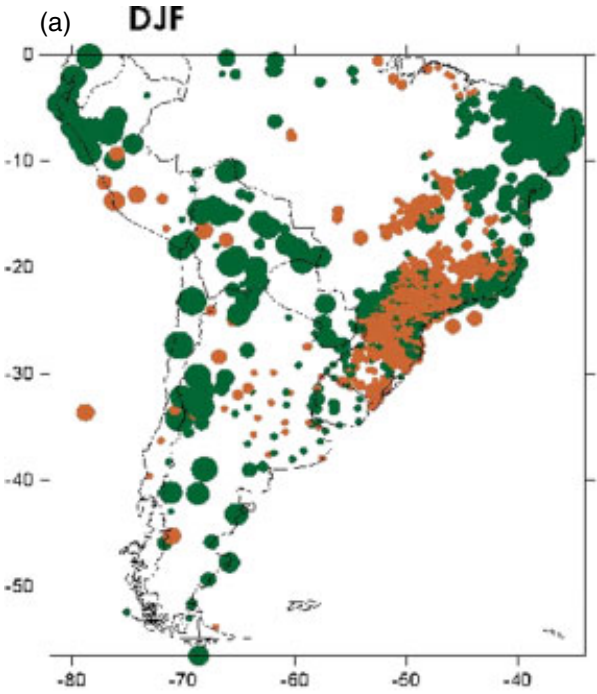

(b) MAM

(c)

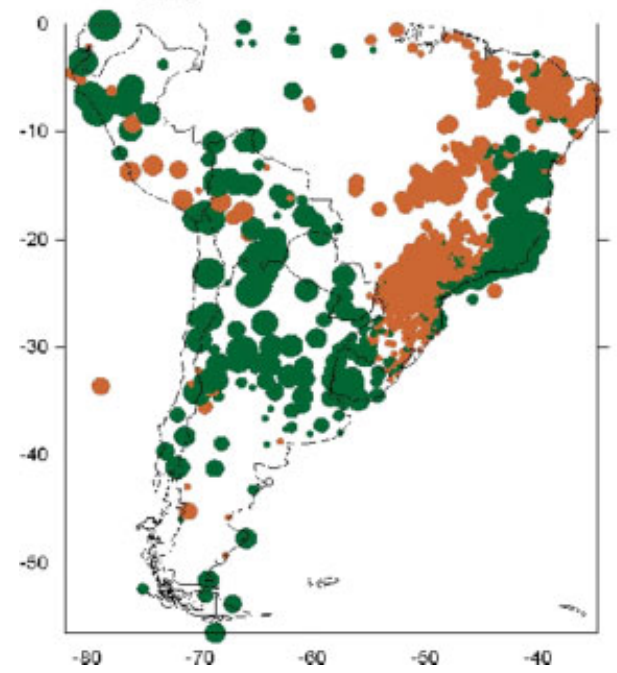

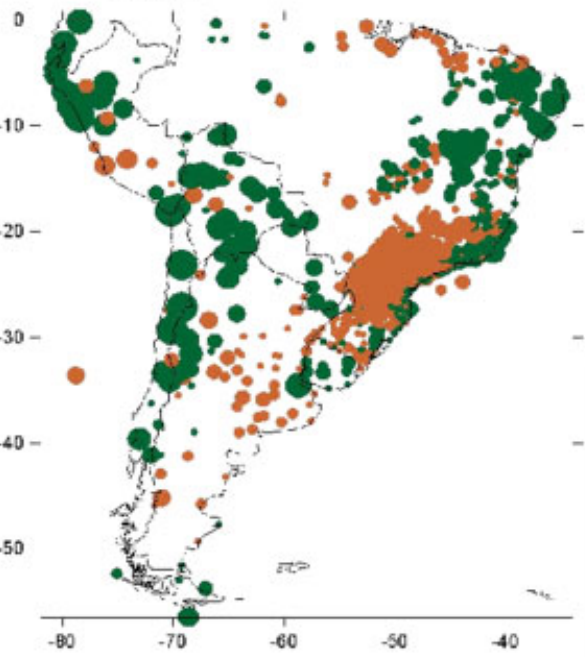

(d) $S O N$

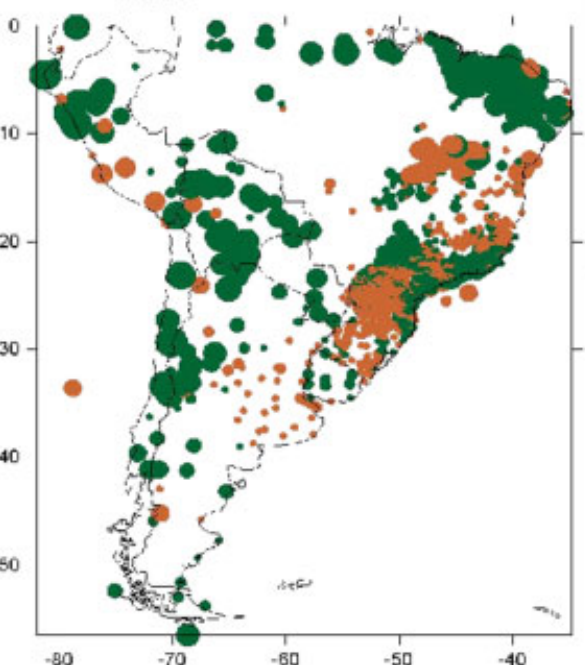

0 to 20

- 20 to 40

- 40 to 60

- 60 to 80

- 80 to 100

- 100 to 120

- 120 to 140

- 140 to 160

- 160 to 180

- 180 to 200

200 to 300

300 to 500

500 to 700

More than 700

Figure 5. Percentage ratio (\%) between simulated and observed mean precipitation for the period 1979-2003 for the seasons DJF, MAM, JJA and SON. This figure is available in colour online at wileyonlinelibrary.com/journal/joc

presents values well below or well above $100 \%$. Some ratios are common in all the seasons: an underestimation of the precipitation in the southeast of Brazil and south of Peru and an overestimation in Bolivia, Uruguay, north and central Chile and north of Peru.

In JJA, precipitation is greatly overestimated in northeastern and central Argentina, which does not occur in the other seasons. In this region, JJA is the dry season, so precipitation totals are very small (which could lead to high values of percentage ratio). Another region where the same behaviour is observed is the north of Chile and precisely in this region precipitation totals are very low throughout the year $\left(<0.01 \mathrm{~mm} \mathrm{day}^{-1}\right)$, so overestimations are also great trough all the year.

Figure 6 displays the annual cycle of mean precipitation (1979-2003) for both the model and the observations in the following regions: central Andes (CA), Altiplano (AL), Paraguay (PA), southeastern Brazil (SEB), subtropical Andes (SUA), Cuyo (CU), La Plata Basin (LPB), southern Brazil (SB), southern Pampas (SP), southeastern Pampas (SEP), southern Andes (SA) and Argentinean
Patagonia (AP). These regions were chosen following the selection of Solman et al. (2008) (The regions are included in Figure 6 herein). The phase of the annual cycle of precipitation is well represented by the model in all of the regions although in some of them, such as SUA, AL and PA, the amplitude is overestimated. There is better agreement between the simulated and the observed annual cycle of precipitation in the other regions, with small differences between data. It could be seen from the figure that the model performs worse over mountainous regions than over plain areas.

\subsection{Interannual variability}

The standard deviation of surface air temperature for both observed and simulated data averaged over the regions of defined by Solman et al. (2008) is shown in Figure 7. Standard deviations were calculated at each meteorological station using both observed and simulated data (the nearest grid point to the meteorological station, Section 3). Standard deviations were then averaged over the selected regions. In general, all regions present an 

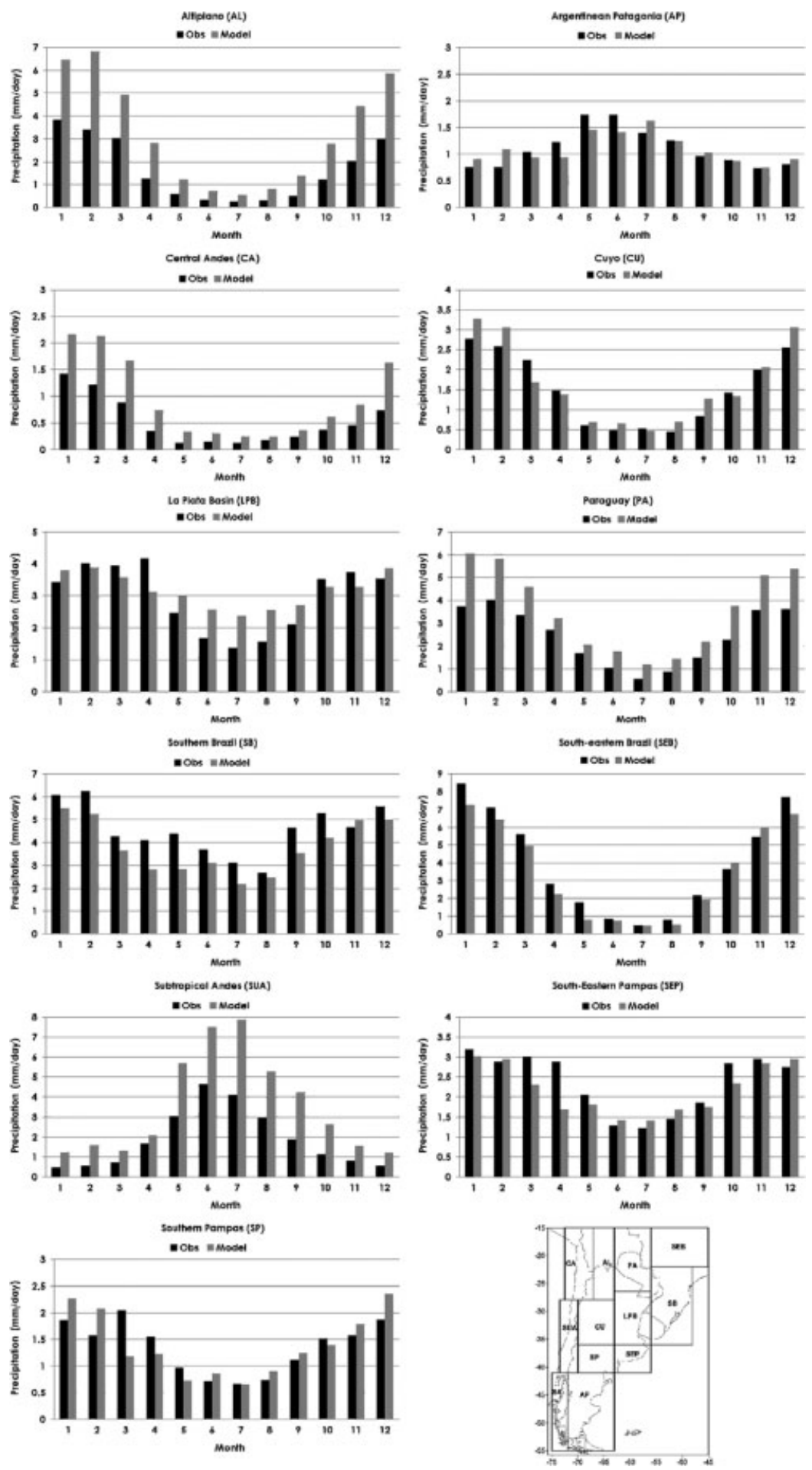

Figure 6. Annual cycle of mean precipitation $\left(\mathrm{mm} \mathrm{day}^{-1}\right)$ for the period 1979-2003. Grey bars represent the simulation and black bars the observations.

observed interannual variability of around $1{ }^{\circ} \mathrm{C}$ in all the seasons. Instead, Figure 7 shows that in all seasons, except JJA, interannual variability is overestimated by MRI/JMA model and it is greater in DJF and MAM. JJA is the season with the best model performance, especially in the ST and SESA regions.

Precipitation over South America displays significant interannual variability. Therefore, it is very important investigate how climate models represent such variability.
Some aspects of the year-to-year precipitation variability over the mentioned area are discussed by Vera et al. (2006b). Figure 8 displays the coefficients of variation of precipitation for both observed and simulated data averaged over some of the regions included in Figure 6. In this case, precipitation coefficients of variation were calculated for 8 of the 11 regions because there are not enough meteorological stations in some zones of the studied region. Taking into account all regions and 

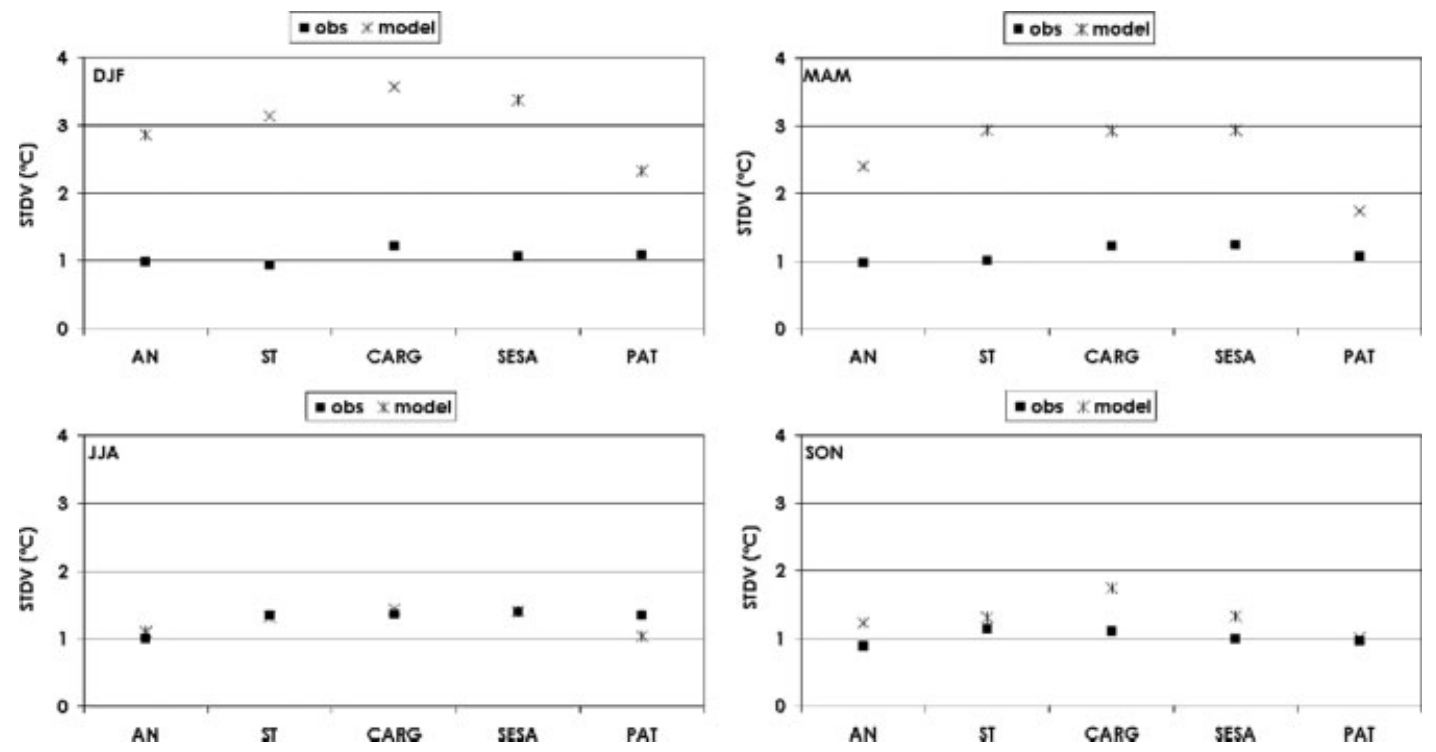

Figure 7. Interannual standard deviation of surface temperature $\left({ }^{\circ} \mathrm{C}\right)$ averaged over five regions defined by Solman et al. (2008) for the seasons DJF, MAM, JJA and SON. Crosses represent the simulations and squares the observations.
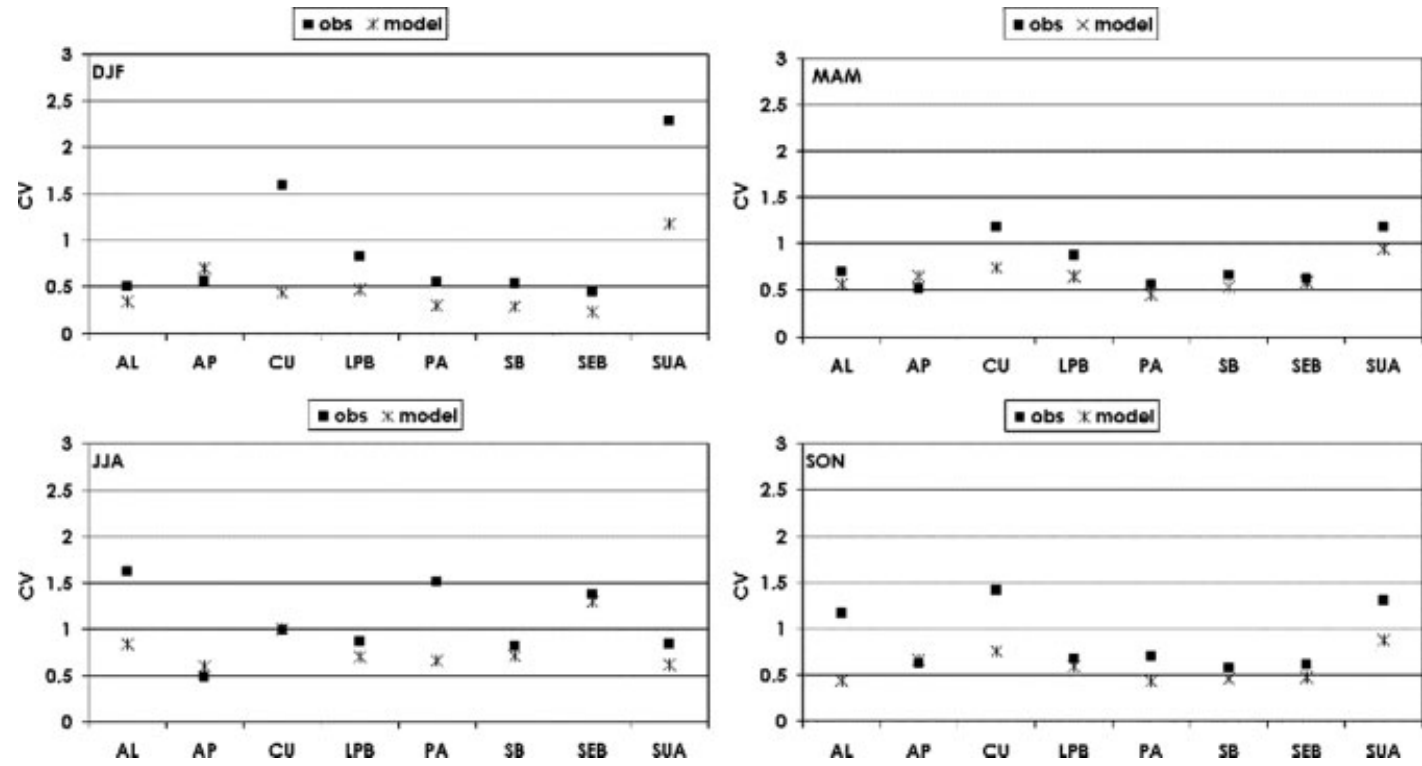

Figure 8. Interannual coefficient of variation for precipitation averaged over eight regions defined by Solman et al. (2008) for the seasons DJF, MAM, JJA and SON. Crosses represent the simulations and squares the observations.

all seasons, the variability of observed precipitation is between 0.44 and 2.28 while the simulated variability is between 0.22 and 1.28 , which indicates that variability in the observations is larger than in the simulation. The model tends to underestimate the $\mathrm{CV}$ in all the seasons and all the regions, except AP. These results differ from those of Solman et al. (2008), who found that in DJF the $\mathrm{CV}$ in the regional model is greater than in the observations (except in SA region), although the global model (the one who was used like boundary conditions) has lower variability than observations. It could be very interesting to analyse the spatial structure of year-to-year variability and whether the JMA/MRI model is able to reproduce the seasonal changes of such variability. So, the observed (as depicted by GPCP dataset) and the simulated seasonal standard deviations of precipitation are shown in Figure 9. Although the resolution of the observational database is too coarse compared with the MRI/JMA model, the database was used to explore the interannual variability over land areas as well as over the oceans, which would have been impossible using only station data. All seasons have a common characteristic: the largest year-to-year variability occurs in the regions where mean precipitation is high. This characteristic was also found by Vera and Silvestri (2009) using some of the WCRP-CMIP3 global models. Most of the DJF variability (Figure 9(a)) is located over the SACZ region. The simulated maximum is shifted to the southeast over the ocean and the variability intensity is similar to the observed one. A secondary maximum 

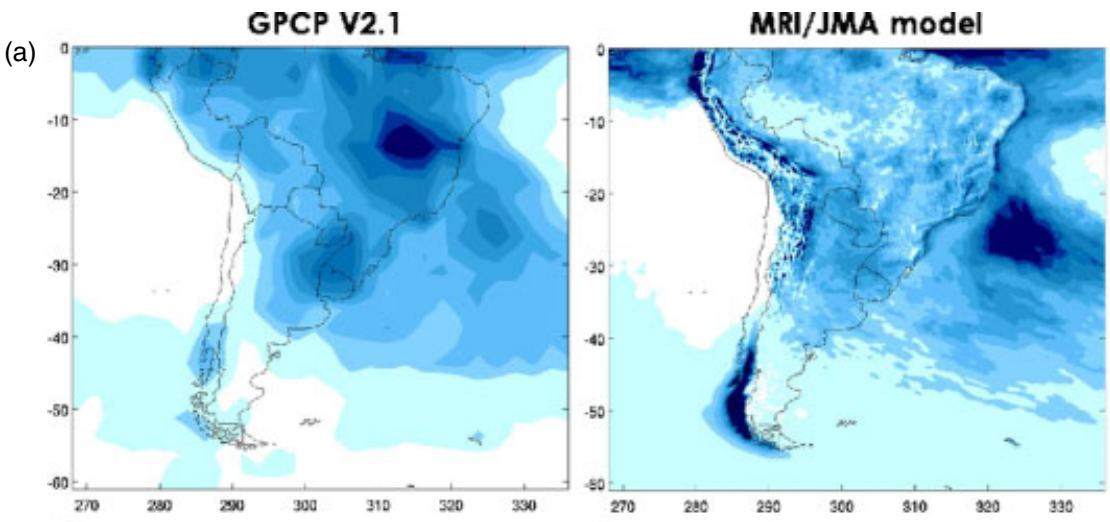

(b)
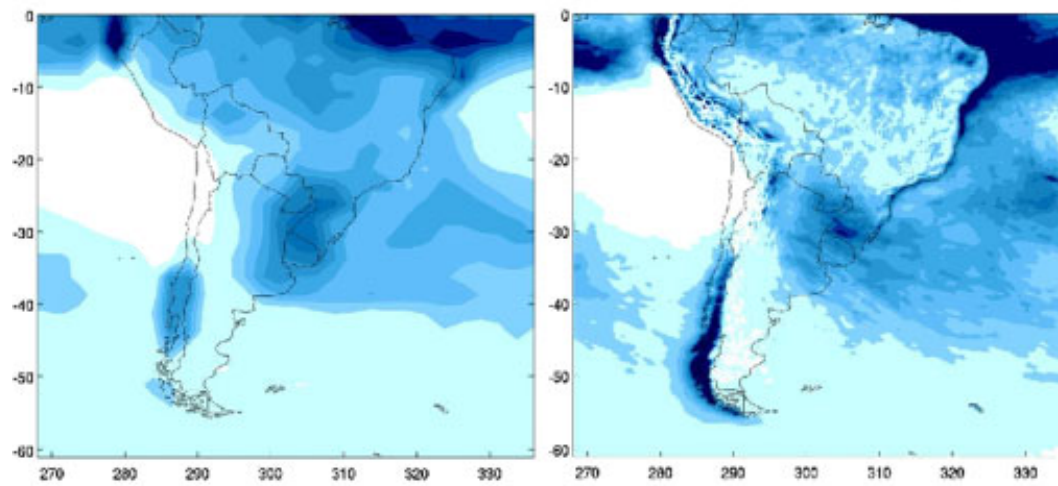

(c)
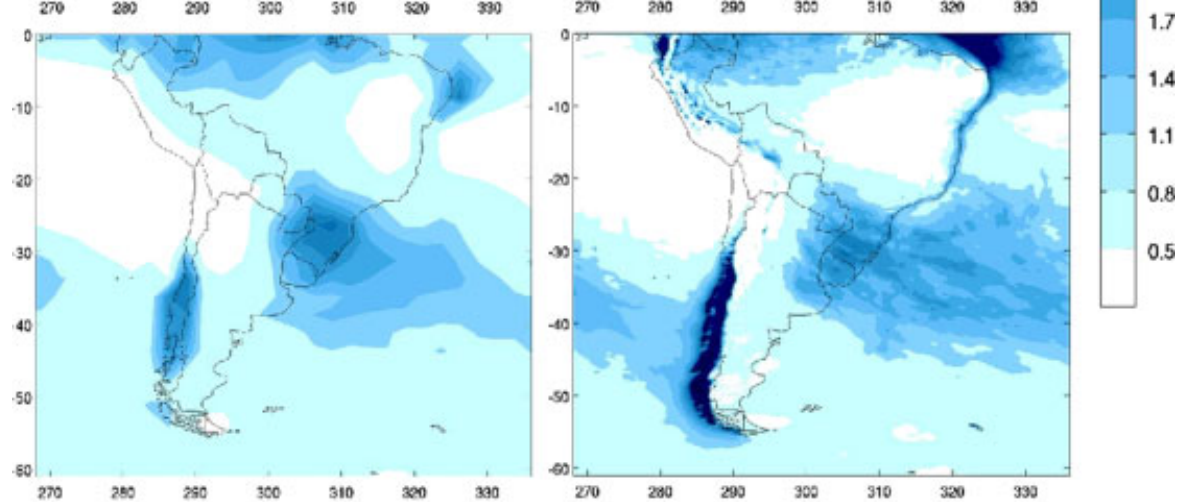

(d)

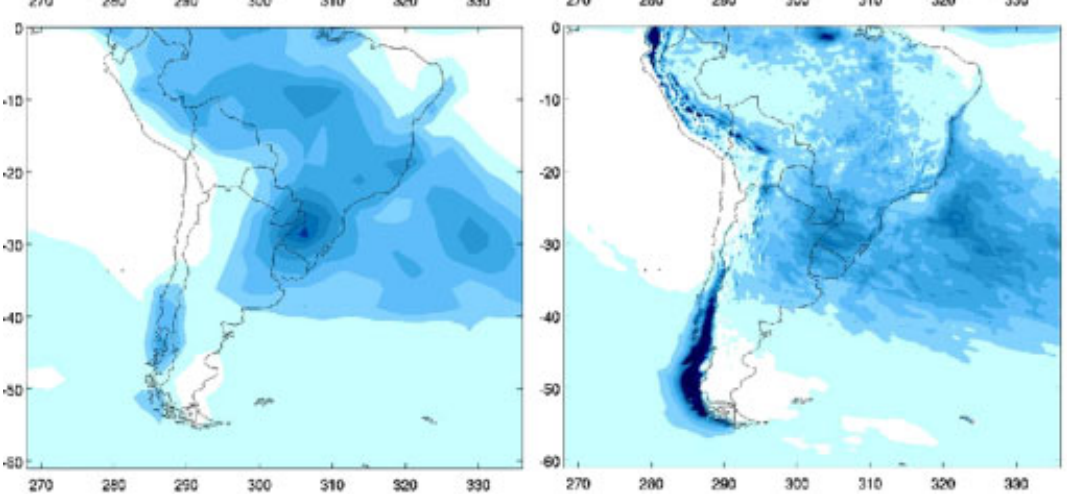

Figure 9. Standard deviation of precipitation in $\mathrm{mm} \mathrm{day}^{-1}$ for GPCP version 2.1 and the JMA/MRI model. (a) DJF, (b) MAM, (c) JJA and (d) SON. This figure is available in colour online at wileyonlinelibrary.com/journal/joc

is evident over the ITCZ, which is also displaced to the southeast in the simulation. Other maxima of yearto-year variability appear over the south of Chile and central and northern Andes, although such maximum is overestimated by the model. This overestimation could be expected because mean precipitation values of GPCP (not shown) over the Andes region are very small. On the other hand, the MRI/JMA model reproduces a mean precipitation maximum over the mentioned area which is also evident in the atlas of the World Meteorological Organization (WMO) compiled by Hoffman (1975), who used more than 1700 meteorological stations to construct the 1931-1960 climatology. So, the maximum in mean precipitation simulated by the model is likely to exist, 

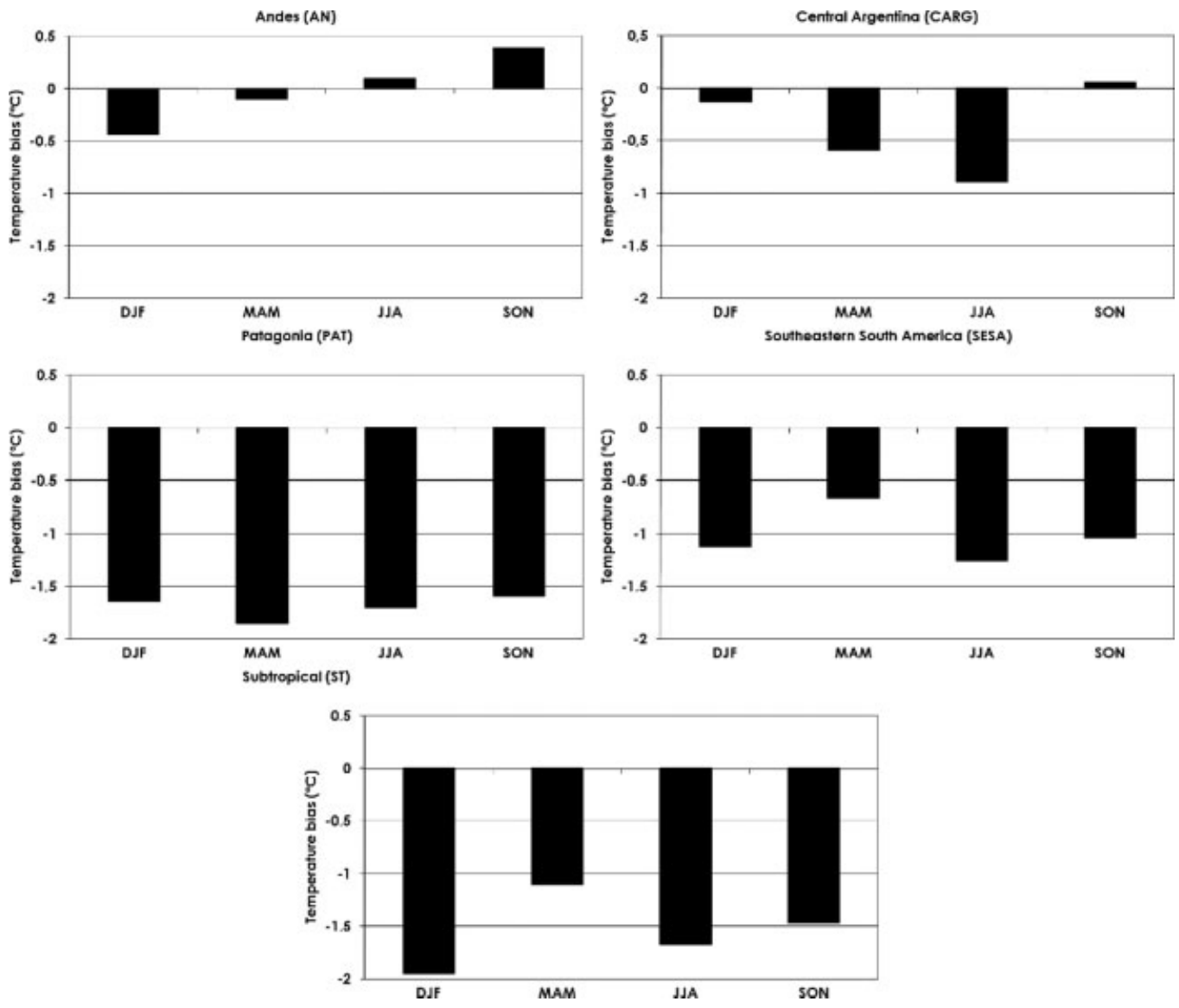

Figure 10. Temperature bias $\left({ }^{\circ} \mathrm{C}\right)$ by season, for the five regions of Figure 4.

but the present poor availability of station data limits the model validation. During MAM (Figure 9(b)), the model simulates the maxima that are evident in the observations (over the northeast of Argentina, northern Andes and tropical Atlantic) with the appropriate values. In JJA (Figure 9(c)), the standard deviations of the simulations are similar to those of the GPCP database, except over the tropical Atlantic and the south of Chile. As mentioned previously, the fact that the latter maximum is not present in the observations is because of the lack of precipitation measurements over that area too. The model also reproduces adequately the maximum of observed JJA variability located over subtropical latitudes. Finally, in SON (Figure 9(d)), the zone with the maximum observed interannual variability is located over subtropical latitudes. Although the observed maximum over the northeast of Argentina appears in the simulation, its intensity is slightly underestimated. Finally, if the high resolution MRI/JMA global model is compared with coarser grid global models (Vera and Silvestri, 2009), it is clear that the high resolution improves the representation of many details of observed variability.

\subsection{Seasonal errors}

Biases were calculated for all the seasons and all the regions defined previously for both temperature and precipitation. It was decided to use the bias as measure of model error. So, if the observations are suppose to be perfect, bias values are due to model error only. The bias was calculated for the period 1979-2003, first at the location of each meteorological station (also considering the nearest grid point of the model, Section 3) and then averaged over the regions. Figure 10 shows the bias of surface air temperature by season. Most of regions present cold biases in all the seasons with values reaching $-2{ }^{\circ} \mathrm{C}$. The regions which present the largest values of biases are those located to the south (PAT), to the northeast (ST) and to the east (SESA) of the domain studied.

The bias for precipitation by season is shown in Figure 11. It was not possible to calculate the bias for all the regions defined in Section 4.1.3. This is because of the gaps in the data of some meteorological stations. This figure displays biases values between 3 and $-1 \mathrm{~mm} \mathrm{day}^{-1}$. In particular, dry biases were found over regions located southeast of Brazil (SEB and SB) in most of the seasons. On the other hand, the regions AL, SUA and PA present wet biases during all the years. If Figures 6 and 11 are compared, it could be seen that generally the greatest values of biases are found in the rainy season of the region.

\subsection{Trends}

Temperature trends in South America were analysed in different regions. Marengo (2001, 2003) and Sansigolo et al. (1992) identified some areas in Brazil with positive 

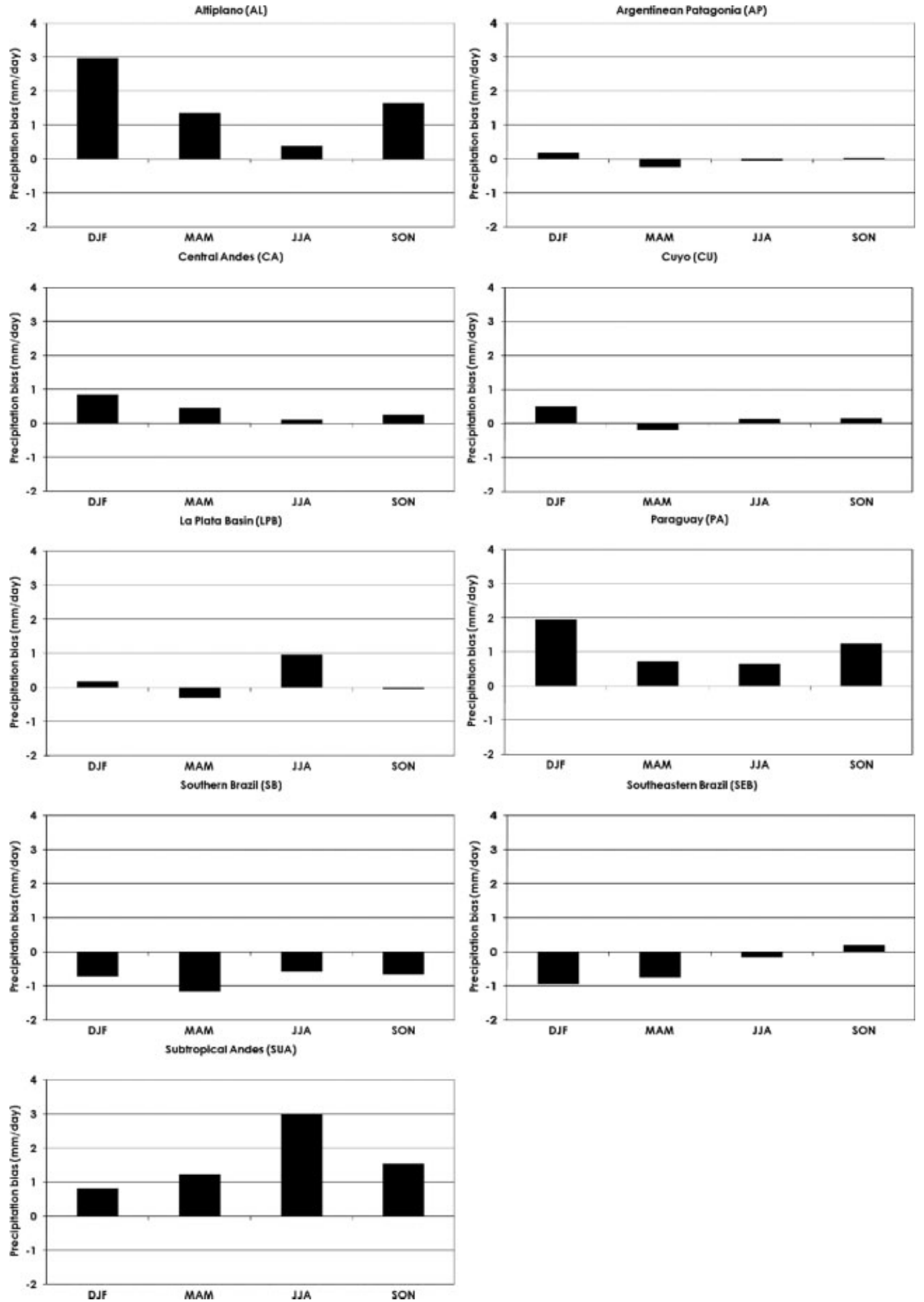

Figure 11. Precipitation bias (in mm day ${ }^{-1}$ ) by season, for nine regions of Figure 6.

trends in the observed temperature, which could be due to land-use changes and development of large cities. On the contrary, over most regions in Argentina observed temperature trends have been negative in the last part of the 20th century, associated with a drop in maximum temperatures and increased minimum temperatures (Nuñez et al., 2008). Figure 12 displays the trend for surface temperature averaged over the regions defined previously. Observations indicate that in the subtropical region (ST) trends are positive in all the seasons. However, except in DJF, trends are always negative in the region located to the south of the studied area (PAT). Trends are positive in the SESA region in all the seasons, except in MAM. Central Argentina (CARG) and central and northern Andes (AN) present positive trends in DJF, JJA and SON, and a negative one during MAM. The comparison with the model shows a wide range of results. During DJF and SON, the trend signs of the simulation are in agreement 

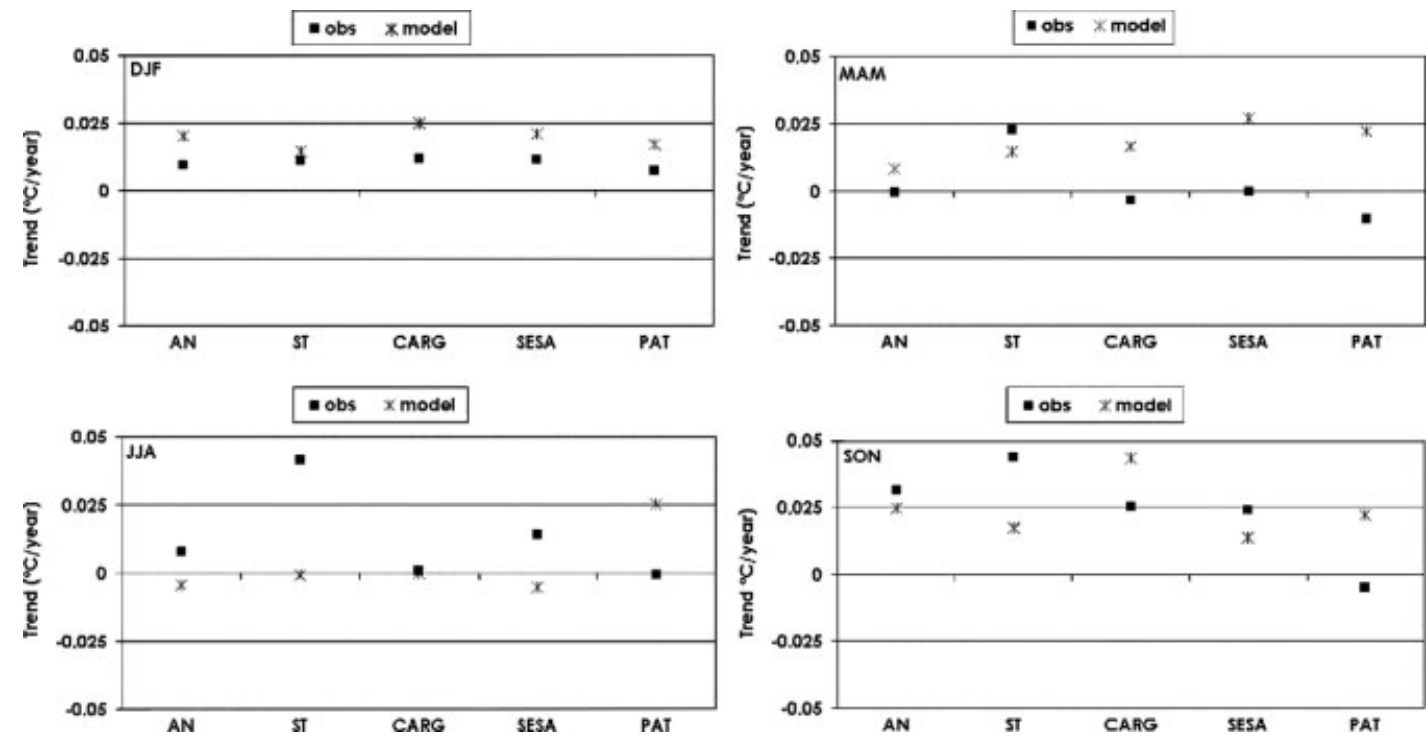

Figure 12. Trend for surface temperature $\left({ }^{\circ} \mathrm{C}\right.$ year $\left.{ }^{-1}\right)$ averaged over the five regions of Figure 4 for the seasons DJF, MAM, JJA and SON. Crosses represent the simulations and squares the observations.
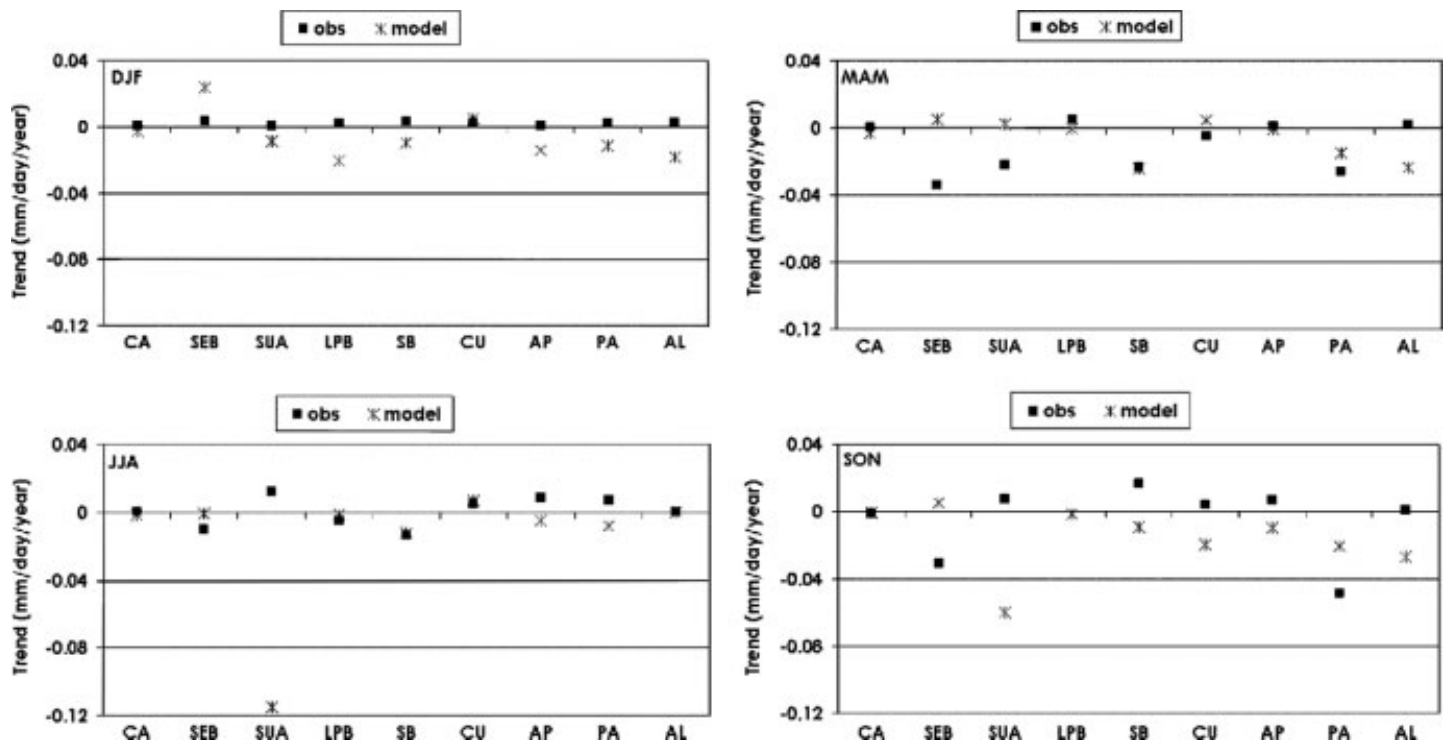

Figure 13. Trend of precipitation (mm day ${ }^{-1}$ year $^{-1}$ ) averaged over nine regions of Figure 6 for the seasons DJF, MAM, JJA and SON. Crosses represent the simulations and squares the observations.

with the observations over the regions located in midand subtropical latitudes. In the other seasons, the model could not capture the positive/negative sign of the trends in most of regions.

Since the second half of the 20th century some regions of South America $\left(22-45^{\circ} \mathrm{S}\right.$, east of the Andes) have shown an important positive trend in annual precipitation (Castañeda and Barros, 1994; Castañeda and Barros, 2001). According to Barros et al. (2000) such behaviour is mainly due to the enhancement of the El NiñoSouthern Oscillation (ENSO) phenomenon at the end of the 1970s (which has maximum positive correlation with precipitation in northern Argentina and southern Brazil). Figure 13 shows the precipitation trends for the period 1979-2003 averaged over nine regions defined previously. In the figure, the observed trends are very small in all the regions in DJF and JJA. Regions located in central and western Argentina and over central Chile (CU and SUA), to the south of the studied area (AP) and in the northern part of the domain (AL, CA) present generally a positive observed trend in all the seasons. In particular, the positive trend in the south of the domain is in agreement with Castañeda and González (2008). On the other hand, SEB region presents negative observed trends in all the seasons, except for the DJF. Although there is substantial divergence between simulated and observed precipitation trends, Figure 13 shows that in some regions and seasons the model matches the observations (CU in DJF, SB in MAM, SB and $\mathrm{AL}$ in JJA and CA in SON). In general, it can be seen 
from Figure 13 that the model tends to simulate negative trends of precipitation over the entire domain while the observed one is in general positive.

\section{Summary and conclusions}

This is an assessment of a present climate simulation over southern South America performed with the MRI/JMA high resolution global model. Climate means, interannual variability and biases were analysed in a 25 -year simulation and compared with wind data from the ECMWFERA40 reanalysis, as well as with temperature and precipitation data from meteorological stations.

Broadly speaking, the model captures the main patterns of low- and upper-level circulation. The LLJ and the westerlies, at low atmospheric levels, are well reproduced by the model in all the seasons but their speeds are generally underestimated. At upper levels, the Bolivian High is well captured by the model but the westerlies are overestimated over central Argentina, especially in JJA.

During DJF, MAM and SON, the MRI/JMA global model underestimates the temperature over east of Argentina, west of Uruguay, south of Chile and over tropical latitudes, while overestimates are observed over central Argentina. This behaviour was found in other climatic simulations but it is worth to highlight that over central Argentina the high resolution global model presents smaller errors than the previous studies. On the other hand, in JJA, the model underestimates the temperature over most of Argentina, south of Chile and to the north of $20^{\circ} \mathrm{S}$. The annual cycle of mean temperature was well captured by the model in all the regions, but the temperature values were generally underestimated mainly in the regions located in the south and east of the studied area.

Regarding precipitation, the model presents a common behaviour in all the seasons: an underestimation of the precipitation in the southeast of Brazil and south of Peru and an overestimation in Bolivia, Uruguay, north and central Chile and north of Peru. During the dry season (JJA) the model greatly overestimates the precipitation over northeastern and central Argentina, so one can assume that the MRI/JMA model fails to reproduce small values of precipitation. In most regions, the phase of the annual cycle of mean precipitation is well captured by the model; however, in some regions (subtropical Andes, Altiplano and Paraguay) the amplitude is overestimated. It is also worth mentioning that in the regions located over mountainous areas the model presents a poor reproduction of the annual cycle.

In general, the model overestimates temperature interannual variability in all regions and all seasons, except in JJA. The model was found to simulate larger variability than the observations, which is opposite to what was found for precipitation. In general, measured precipitation tends to be more variable than the simulations in most of the studied regions. The analysis of the spatial structure of year-to-year variability during all the seasons showed agreement with the mean precipitation, pointing out that the regions with the largest mean precipitation also presented high variability. In general, the model was found to perform well in representing the spatial structure interannual variability of precipitation, although were found some patterns of year-to-year variability misplaced. In particular, in DJF, the model shifted the variability maxima (related with the SACZ and ITCZ) to the southeast. Despite these deficiencies, it is worth to highlight that the high resolution of the MRI/JMA global model improves the representation of many details of observed variability if it is compared with coarser mesh global models (Vera and Silvestri, 2009).

Biases for temperature and precipitation were calculated for both the observed and simulated data. Most of regions present cold biases in all the seasons. The largest biases (around $-2{ }^{\circ} \mathrm{C}$ ) were found over PAT, SESA and ST regions. On the other hand, it was found precipitation biases between 3 and $-1 \mathrm{~mm}^{-1 a y}{ }^{-1}$ in all the regions and seasons. Dry biases were found over SEB and SB, whereas AL, SUA and PA regions showed wet bias in most of seasons.

Regarding temperature trends, it was found that only during DJF and SON, simulated trend's signs are in agreement with the observations over the regions located in mid- and subtropical latitudes. Significant divergence between observed and simulated precipitation trends was observed; moreover, it was found that observed precipitation trends are generally positive whereas simulated ones are negative.

Although the representation of the present climate for southern South America by the MRI/JMA model has its deficiencies like most of models, it is important to highlight that the high resolution of this global model is crucial to represent some details of temperature and precipitation variables that other coarse models were not able to capture. In this paper it has been shown that the high resolution of the MRI/JMA model allowed representing features of the interannual variability of precipitation that coarse resolution global models could not (Vera and Silvestri, 2009). On the other hand, if the MRI/JMA model simulation is compared with previous regional climate models experiments it could be concluded that in general the MRI/JMA model reproduces with less error the observed data (temperature or precipitation). This improvement not only has to be with the high resolution that this model has, but also with the suppression of boundary problem, which imply not to drag the driven model errors.

For the above, it can be concluded that the MRI/JMA high resolution global model is a good tool to represent the present climate in southern South America and might also be used to simulate future climate changes, taking this assessment into consideration.

\section{Acknowledgements}

The authors wish to thank two anonymous reviewers for the valuable comments and suggestions which contribute to improve this study. The authors also thank 
the Meteorological Research Institute (MRI) for providing the model data and the Weather Service of Argentina, the National Center for Atmospheric Research (NCAR), the National Water Agency from Brazil and the CLARIS-LPB Project (A Europe-South America Network for Climate Change Assessment and Impact Studies in La Plata Basin) for providing the observed data. GPCP Precipitation data were downloaded from the web site of the NOAA/OAR/ESRL PSD, Boulder, Colorado, USA: http://www.esrl.noaa.gov/psd/. This work was partially supported by UBACYT-X160, PIP CONICET 112200801-00195 and CLARIS-LPB.

\section{References}

Adler RF, Huffman GJ, Chang A, Ferraro R, Xie P, Janowiak J, Rudolf B, Schneider U, Curtis S, Bolvin D, Gruber A, Susskind J, Arkin P. 2003. The Version 2 Global Precipitation Climatology Project (GPCP) Monthly Precipitation Analysis (1979-Present). Journal of Hydrometeorology 4: 1147-1167.

Alves LM, Marengo JA. 2010. Assessment of regional seasonal predictability using the PRECIS regional climate modeling system over South America. Theoretical and Applied Climatology 100: 337-350, DOI: 10.1007/s00704-009-0165-2.

Barros V, Castañeda E, Doyle M. 2000. Recent precipitation trends in Southern South America to the east of the Andes: an indication of a mode of climatic variability. Southern Hemisphere Paleo and Neoclimates Key-Sites, Methods, Data and Models. Springer: Berlin, 187-206.

Bidegain M, Camilloni I. 2006. Performance of GCMs and climate future scenarios for southeastern South America. In Proceedings of 8 ICSHMO, Foz do Iguaçu, Brazil, April 24-28, 2006, INPE, $223-226$.

Cabré MF, Solman S, Nuñez MN. 2010. Creating regional climate change scenarios over southern South America for the 2020's and 2050's using the pattern scaling technique: validity and limitations. Climatic Change 98: 449-469, DOI: 10.1007/s10584-009-9737-5.

Carril AF, Menéndez CG, Nuñez MN. 1997. Climate change scenarios over the South American region: an intercomparison of coupled general atmosphere-ocean circulation models. International Journal of Climatology 17: 1613-1633.

Castañeda ME, Barros V. 1994. Las tendencias de la precipitación en el Cono sur de América al Este de los Andes. Meteorológica 19: $23-32$.

Castañeda ME, Barros V. 2001. Tendencias de la precipitación en el oeste de Argentina. Meteorológica 26: 5-23.

Castañeda ME, González MH. 2008. Statistical analysis of the precipitation trends in the Patagonia region in Southern South America. Atmósfera 21(3): 303-317.

De Sales F, Xue Y. 2006. Investigation of seasonal prediction of the South American regional climate using the nested model system. Journal of Geophysical Research 111: D20107, DOI: 10.1029/2005JD006989.

Gandu AW, Silva Dias PL. 1998. Impact of tropical heat sources on the South American tropospheric upper circulation and subsidence. Journal of Geophysical Research 103(D6): 6001-6015.

Giorgi F, Bi X, Pal JS. 2004. Mean, interannual variability and trends in a regional climate change experiment over Europe. I: present day climate (1961-1990). Climate Dynamics 22: 733-756, DOI: 10.1007/s00382-004-0409-x.

Hoffman J. 1975. Maps of mean temperature and precipitation. Climatic Atlas of South America, vol. 1. World Meteorological Organization: Geneva, Switzerland, 1-28.

Kitoh A, Kusunoki S, Nakaegawa T. 2011. Climate change projections over South America in the late 21st century with the 20 and $60 \mathrm{~km}$ mesh Meteorological Research Institute atmospheric general circulation model (MRI-AGCM). Journal of Geophysical Research 116: D06105, DOI: 10.1029/2010JD014920.

Labraga LC, Lopez M. 1997. A comparison of the climate response to increased carbon dioxide simulated by general circulation models with mixed-layer and dynamic ocean representations in the region of South America. International Journal of Climatology 17: $1635-1650$
Lenters JD, Cook KH. 1997. On the origin of the Bolivian High and related circulation features of the South American climate. Journal of the Atmospheric Sciences 54: 656-678.

Liebmann B, Kiladis GN, Vera CS, Saulo AC, Carvalho LMV. 2004. Subseasonal variations of rainfall in South America in the vicinity of the low-level jet east of the Andes and comparison to those in the South Atlantic Convergence Zone. Journal of Climate 17: $3829-3842$.

Marengo J. 2001. Mudanças climáticas globais e regionais: avaliação do clima atual do Brasil e projeções de cenários climáticos do futuro. Reista. Brasileria de Meteorologia 16: 1-18.

Marengo J. 2003. Condições climáticas e recursos hídricos no Norte Brasileiro. In Clima e Recursos Hídricos no Brasil, Tucci CE, Braga B (eds). Associação Brasileira de Recursos Hídricos FBMC/ANA: Porto Alegre, Brazil, 117-161.

Marengo JA, Jones R, Alves LM, Valverde MC. 2009. Future change of temperature and precipitation extremes in South America as derived from the PRECIS regional climate modeling system. International Journal of Climatology 29: 2241-2255, DOI: 10.1002/joc. 1863.

Mellor GL, Yamada T. 1974. A hierarchy of turbulence closure models for planetary boundary layers. Journal of the Atmospheric Sciences 31: 1791-1806.

Mellor GL, Yamada T. 1982. Development of a turbulence closure model for geophysical fluid problems. Reviews of Geophysics 20 : $851-875$.

Mizuta R, Oouchi K, Yoshimura H, Noda A, Katayama K, Yukimoto S, Hosaka M, Kusunoki S, Kawai H, Nakagawa M. 2006. 20$\mathrm{km}$-mesh global climate simulations using JMA-GSM model. Journal of the Meteorological Society of Japan 84: 165-185.

Nuñez MN, Ciapessoni HH, Rolla A, Kalnay E, Cai M. 2008. Impact of land use and precipitation changes on surface temperature trends in Argentina. Journal of Geophysical Research 113: D06111, DOI: 10.1029/2007JD008638.

Nuñez MN, Solman SA, Cabré MF. 2009. Regional climate change experiments over southern South America. II: climate change scenarios in the late twenty-first Century. Climate Dynamics $\mathbf{3 2}$ 1081-1095, DOI: 10.1007/s00382-008-0449-8.

Penalba OC, Robledo F. 2010. Spatial and temporal variability of the frequency of extreme daily rainfall regime in the La Plata Basin during the 20th century. Climatic Change 98: 531-550, DOI: 10.1007/s10584-009-9743-7.

Pesquero JF, Chou SC, Nobre CA, Marengo JA. 2009. Climate downscaling over South America for 1961-1970 using the Eta model. Theoretical and Applied Climatology 99: 75-93, DOI: 10.1007/s00704-009-0123-z.

Rayner NA, Parker DE, Horton EB, Folland CK, Alexander LV, Rowell DP, Kent EC, Kaplan A. 2003. Global analyses of sea surface temperature, sea ice, and night marine air temperature since the late nineteenth century. Journal of Geophysical Research 108(D14): 4407, DOI: 10.1029/2002JD002670.

Salio P, Nicolini M, Zipser EJ. 2007. Mesoscale convective systems over Southeastern South America and its relationship with the South American low level jet. Monthly Weather Review 135: 1290-1309, DOI: 10.1175/MWR3305.1.

Sansigolo C, Rodriguez R, Etchichury P. 1992. Tendências nas temperaturas médias do Brasil. CongressoBrasileiro de Meteorologia, Vol. 1. Brasileiro de Meteorologia: Sao Paulo, Brazil, 367-371.

Sato N, Sellers PJ, Randall DA, Schneider EK, Shukla J, Kinter JL, III, Hou Y-T, Albertazzi E. 1989a. Implementing the simple biosphere model in a general circulation model: methodologies and results. NASA Contractor Report 185509, Center for Land-OceanAtmosphere Interactions, University of Maryland at College Park, 76.

Sato N, Sellers PJ, Randall DA, Schneider EK, Shukla J, Kinter JL, III. Hou Y-T, Albertazzi E. 1989b. Implementing the simple biosphere model in a general circulation model. Journal of the Atmospheric Sciences 46: 2757-2782.

Seth A, Rojas M, Rauscher SA. 2010. CMIP3 projected changes in the annual cycle of the South American Monsoon. Climatic Change $\mathbf{9 8}$ 331-357, DOI: 10.1007/s10584-009-9736-6.

Silvestri G, Vera C, Jacob D, Pfeifer S, Teichmann C. 2008. A highresolution 43-year atmospheric hindcast for South America generated with the MPI regional mode. Climate Dynamics 32: 693-709, DOI: $10.1007 / \mathrm{s} 00382-008-0423-5$. 
Solman SA, Nuñez MN, Cabré MF. 2008. Regional climate change experiments over southern South America. I: present climate. Climate Dynamics 30: 533-552, DOI: 10.1007/s00382-007-0304-3.

Solman SA, Sánchez E, García-Ochoa R, Berbery H, Samuelsson P, Reca Remedio A, Chou SC, Marengo J, Porfirio da Rocha R, Li L, Pessacg N, Menendez C. 2011. Modeling South America regional climate for present conditions from an ensemble of RCMs: model performance and uncertainties. Geophysical Research Abstracts 13 EGU2011-12351.

Uppala SM, Uppala SM, Kallberg PW, Simmons AJ, Andrae U, Bechtold VD, Fiorino M, Gibson JK, Haseler J, Hernandez A, Kelly GA, Li X, Onogi K, Saarinen S, Sokka N, Allan RP, Andersson E, Arpe K, Balmaseda MA, Beljaars ACM, Van De Berg L, Bidlot J, Bormann N, Caires S, Chevallier F, Dethof A, Dragosavac M, Fisher M, Fuentes M, Hagemann S, Holm E, Hoskins BJ, Isaksen L, Janssen PAEM, Jenne R, McNally AP, Mahfouf JF, Morcrette JJ, Rayner NA, Saunders RW, Simon P, Sterl A, Trenberth KE, Untch A, Vasiljevic D, Viterbo P, Woollen J.
2005. The ERA-40 re-analysis. Quaterly Journal of the Royal Meteorological Society 131: 2961-3012.

Vera C, Silvestri G, Liebmann B, González P. 2006a. Climate change scenarios for seasonal prediction in South America from IPCCAR4 models. Geophysical Research Letters 33: L13707, DOI: 10.1029/2006GL025759.

Vera C, Higgins W, Amador J, Ambrizzi T, Garreaud R, Gochis D, Gutzler D, Lettenmaier D, Marengo J, Mechoso C, NoguesPaegle J, Silva Dias P, Zhang C. 2006b. Toward a unified view of the American monsoon systems. Journal of Climate 19: 4977-5000.

Vera C, Silvestri G. 2009. Precipitation interannual variability in South America from the WCRP-CMIP3 multi-model dataset. Climate Dynamics 32: 1003-1014, DOI: 10.1007/s00382-009-0534-7.

Vera C, Vigliarolo PK, Berbery EH. 2002. Cold season synoptic-scale waves over subtropical South America. Monthly Weather Review 13: 684-699, DOI: 10.1175/1520- 0493 (2002)130<0684:CSSSWO> 2.0.CO;2. 